This is the accepted versión of an article published in Oecologia (Springer-Verlag). Published online: 30 June 2015.

The final publication is available at Springer via DOI 10.1007/s00442-015-3377-4

\title{
Assessing coexisting plant extinction debt and colonization credit in a grassland-forest change
}

\section{gradient}

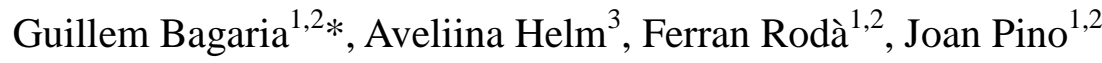

${ }^{1}$ CREAF, Cerdanyola del Vallès 08193, Spain

${ }^{2}$ Univ Autònoma Barcelona, Cerdanyola del Vallès 08193, Spain

${ }^{3}$ Institute of Ecology and Earth Sciences, University of Tartu, Lai 40, 51005 Tartu, Estonia

*Correspondence: Guillem Bagaria, CREAF, Cerdanyola del Vallès 08193, Spain.

E-mail: g.bagaria@creaf.uab.cat

Phone: +34 935814851

FAX: +34935814151

Author Contributions: GB, AH, FR and JP conceived the ideas. GB conducted the field sampling. GB, AH, FR and JP analysed the data. GB wrote the first draft of the manuscript, and all authors contributed substantially to revisions. 


\section{Abstract}

2 Changes in species richness along ecological succession might be strongly determined by coexisting

3 extinction debts of species from the original habitats and colonization credits of those from the

4 replacing habitats. The magnitude of these processes and their causes remain largely unknown. We

5 explored the extinction debt and colonization credit for grassland and forest specialist plants,

6 respectively, and the local and landscape factors associated to richness of these species groups in a

7 50-year forest encroachment process into semi-natural Mediterranean grasslands. A set of sampling

8 plots of persistent grasslands and forests and their transitional habitat (wooded grasslands) were

9 selected within fixed-area sites distributed across the landscape. Results confirmed extinction debt

10 and suggested colonization credit (according to observed trends and model predictions) in wooded

11 grasslands comparing them with persistent forests, despite wooded grasslands and persistent forests

12 having similar tree cover. Grassland connectivity and solar radiation oppositely affected richness of

13 both grassland and forest specialists. Moreover, the availability of seed sources from old forests

14 may accelerate the payment of colonization credit in wooded grasslands. Thus, extinction debt and

15 colonization credit have driven species turnover across 50 years of forest encroachment, but at

16 different rates and being contrastingly affected by local and landscape factors. These findings

17 highlight the importance of documenting biodiversity time lags following habitat change when they

18 are still in progress, in order to timely and adequately manage habitats of high conservation value as

19 the studied grasslands.

21 Keywords Biodiversity change, Habitat change, Mediterranean grasslands, Variegated landscape,

22 Vascular plants. 


\section{Introduction}

29 Land-use dynamics is driving the change of biodiversity patterns for many taxonomic groups all

30 over the world, resulting in either species losses or gains (Fahrig 2003; Baan et al. 2012). Species

31 extinctions and colonizations in dynamic landscapes and habitats often occur with time lags

32 (Jackson and Sax 2010). Both extinction debt (Tilman et al. 1994; Kuussaari et al. 2009) and

33 colonization credit (Jackson and Sax 2010; Cristofoli et al. 2010) have been identified following the

34 changes in habitat quality, amount or connectivity. The relative rate at which extinctions and

35 colonizations occur determines the existence of transient richness surpluses or deficits during the

36 relaxation time (Jackson and Sax 2010). The extinction of remnant populations that persist without

37 completion of the whole life cycle (Eriksson 1996) can be delayed by rescue effect from close

38 populations or by biological characteristics, such as clonal growth or long life-span, which make

39 individuals resistant to decreased habitat quality in particular life-cycle stages (Kuussaari et al.

40 2009; Hylander and Ehrlén 2013; but see Lindborg et al. 2012). Regarding colonization, lags can

41 occur by limited dispersal due to the lack of seed sources (Verheyen et al. 2003b), or by suboptimal

42 local conditions that prevent establishment, survival or reproduction (Sax and Brown 2000;

43 Jacquemyn et al. 2003; Vellend 2005; Piqueray et al. 2013). Thus, both landscape and local

44 environmental factors can determine the occurrence of time lags (Verheyen et al. 2003a; Zulka et al.

45 2014).

46 There is an extensive literature focusing on extinction debt following habitat loss, mainly for

47 plants and butterflies in forests and semi-natural grasslands, and at different spatial and time scales

48 (Helm et al. 2006; Vellend et al. 2006; Krauss et al. 2010; Cousins and Vanhoenacker 2011;

49 Guardiola et al. 2013), but the complementary topic of colonization credit has received much less

50 attention, and empirical evidence is relatively scarce (Pierik et al. 2010; Piqueray et al. 2011;

51 Hylander and Weibull 2012; Lira et al. 2012). Furthermore, the few studies that have investigated

52 the simultaneous occurrence of an extinction debt and a colonization credit have focused on the 
53 dynamics within one habitat type and species group, i.e. the extinctions and colonizations of the

54 same group of specialist species following either habitat degradation or restoration (Hanski 2000;

55 Piqueray et al. 2011; Hylander and Weibull 2012; Lira et al. 2012).

56 European semi-natural grasslands have experienced a severe decline in habitat area due to the cessation of traditional management practices and expansion of arable fields or forests. This landuse change started more than a century ago, but it has become more accentuated over the past 70 years (Eriksson et al. 2002; Adriaens et al. 2006). The increase in forest cover following the

60 depopulation of rural areas was widespread in the Mediterranean Basin during the 20th century, and 61 increased occurrence of forest species and decline of grassland species are expected (Debussche et

62 al. 1999). Compared to the amount of studies from temperate European grasslands, the land-use

63 changes in Mediterranean grasslands have received much less attention. However, due to their high

64 biodiversity and conservational importance, time-lagged effects of habitat change on biodiversity

65 need to be documented and quantified (Guardiola et al. 2013). We focus on investigating the time

66 lags in extinction of grassland specialists and in colonization of forest specialists following forest

67 encroachment into previously open grasslands. During forest encroachment, plant richness is

68 expected to decrease because Mediterranean grasslands usually harbour more species than the

69 resulting forests (Díaz-Villa et al. 2003). However, it is not known to what extent recently

70 encroached grasslands exhibit extinction debt for grassland species and colonization credit for forest

71 species, making the application of effective conservation measures more complicated.

72 In this study we aim to fill the gap in the current knowledge about the simultaneous processes of

73 extinction debt and colonization credit for habitat specialists of the original and the replacing habitat

74 type, respectively, after several decades of habitat change. We investigate the richness balance (i.e.

75 the balance between extinctions and colonizations) for vascular plants and the drivers behind

76 delayed species responses along the forest encroachment gradient of Mediterranean semi-natural

77 grasslands, comparing transition (wooded) grasslands with persistent grasslands and forests (space-

78 for-time substitution). As forest encroachment into Mediterranean landscapes leads to a continuous 
79 landscape gradient rather than to a patchy landscape with sharp habitat boundaries (Bagaria et al.

80 2012), we used a sampling design that fits in with the habitat variegation concept (McIntyre and

81 Barrett 1992), considering gradients of target habitat transformation and suitability. Our main

82 objectives were i) to investigate the magnitude of the extinction debt and colonization credit for

83 grassland specialists and forest specialists, respectively, following a forest encroachment process,

84 and ii) to determine the local and landscape factors involved in extinction of grassland specialist

85 species and colonization of forest specialist species during forest encroachment.

\section{Materials and methods}

90 Study system

91 The study was conducted on the calcareous plateau of Prades Mountains, a relatively small massif

$92(20 \times 16 \mathrm{~km})$ in southern Catalonia, NE Iberian Peninsula $\left(41^{\circ} 14^{\prime}-41^{\circ} 23^{\prime} \mathrm{N}, 0^{\circ} 56^{\prime}-1^{\circ} 10^{\prime} \mathrm{E}\right)$. Our focal

93 habitat was Mediterranean semi-natural calcareous grasslands, which show a vegetation cover

94 between $50 \%$ and $80 \%$ and consist mainly of hemicryptophytes and chamaephytes of $<50 \mathrm{~cm}$ in

95 height (Guardiola et al. 2013). Historically, the study area was subjected to widespread sheep and

96 goat grazing and the landscape was dominated by semi-natural grasslands with small forest patches

97 at the beginning of the 20th century. The forest-grassland mosaic was relatively stable until the

98 1940s, when it is assumed that grasslands underwent a generalized decline due to great reduction or

99 cessation of livestock grazing and forest encroachment (Guardiola et al. 2013), resulting in open

100 forests dominated by Scots pine (Pinus sylvestris L.) and holm oak (Quercus ilex L.) in variable

101 proportions. The study area can be considered relatively homogeneous regarding topographic,

102 geologic and land-use characteristics, and current grazing is sporadic and limited to the lowest

103 areas. Semi-natural calcareous grasslands of Prades are located between 800 and $1200 \mathrm{~m}$ a.s.1. and

104 show mean annual temperature around $11^{\circ} \mathrm{C}$, mean annual precipitation around $750 \mathrm{~mm}$, and 
marked summer drought (Digital Climatic Atlas of Catalonia; www.opengis.uab.cat/acdc).

107 Site selection and sampling design

108 In order to study extinction debt and colonization credit patterns and their associated drivers, plant

109 richness in persistent (grasslands and forests) and in transitional wooded grasslands (i.e. previous

110 grasslands that underwent an important woody encroachment process) was compared for different

111 species groups, and its relationship with local environmental factors such as soil characteristics,

112 solar radiation and grazing, and historical and current landscape was investigated. The continuous

113 habitat transformation in our Mediterranean study system does not match the delimitation of

114 distinctive habitat patches and, hence, a landscape sampling approach, consisting in a regular

115 sampling within fixed-area sites, was used and provides a unique opportunity to study the effect of

116 continuous habitat change on species extinctions and colonizations. We selected 20 sites

117 corresponding to the maximum available landscape diversity in terms of forest and grassland cover

118 proportions, each with a diameter of $200 \mathrm{~m}$. Preliminary site selection was performed on the basis

119 of historical (1956) and current (2009) orthophotomaps and the final selection was made during

120 preliminary fieldwork, seeking for a wide range in historical and current forest cover to allow the

121 study of delays in species extinctions and colonizations. The 20 finally selected sites fulfilled the

122 following requirements: (1) considerably ranged in historical (19-96\%) and current (16-70\%)

123 grassland proportion; (2) were naturally reforested; (3) had no crop fields in the past nor nowadays;

124 (4) were not burned at least during the last 25 years, and (5) were at least 1-km apart from each

125 other to avoid landscape overlap and increase data independence. Historical aerial photographs

126 were obtained from Spanish Army photos with an original scale of ca. 1:30000, and pixel size of the

127 resulting 1-band orthophotomaps was $1 \mathrm{~m}$. The present-day (2009) 3-band orthophotomaps were

128 produced by the Cartographic Institute of Catalonia (www.icc.cat), with a scale of 1:5000 and a

129 pixel size of $0.5 \mathrm{~m}$, and we converted them to a pixel size of $1 \mathrm{~m}$ to make them comparable with the

130 historical ones. From both past (1956) and present (2009) orthophotomaps, 300 training points 
131 randomly distributed on the orthophotomaps were manually assigned by visual photo-interpretation

132 to one of the following categories: forest, grassland, bare ground, crop fields or urban. Then, forest

133 and grassland records from the training points were used to reclassify each orthophotomap based on

134 a pruned classification tree. The misclassification error rate for the historical map was $24 \%$, while it

135 was $19 \%$ for the current map, which has a better quality, but the same inherent problems of complex

136 Mediterranean landscapes and mountainous areas. The classification tree was conducted with rpart

137 package (Therneau et al. 2013) in R programming language (R Development Core Team 2014), and 138 the reclassification was performed using MiraMon GIS (www.miramon.uab.cat). Crop fields, bare

139 ground and urban areas obtained from the land-cover map of Catalonia of 2009

140 (www.creaf.uab.cat/mcsc) and from a land-cover map of the study area of 1956 were combined

141 respectively with the reclassifications of 2009 and 1956 orthophotomaps, to obtain maps with fine-

142 scale transitions from grassland to forest and well-delimited areas for other habitats. The

143 combination of land-cover with reclassified maps was performed using the MiraMon GIS.

145 Recording species occurrences

146 At each of the 20 selected sites, 13 circular plots of $3 \mathrm{~m}$ of diameter were sampled in a regular grid

147 in spring and early summer 2011, each separated $33 \mathrm{~m}$ from neighbour plots (Fig. 1). The small size

148 of the plots was chosen according to the fine-scale habitat changes that result from the forest

149 encroachment process. Each plot was marked with a precision GPS, and all vascular plant species

150 with any aerial part within its boundaries were recorded. Each of the species found during the

151 survey was assigned to one of the following categories, using regional floras (Rivas-Martínez et al.

152 2001; Bolòs et al. 2005) and expert advice: (1) grassland specialists, i.e. plants growing mainly in

153 calcareous grasslands and sparse shrublands; (2) forest specialists, i.e. plants growing mainly in

154 forests, and (3) other, i.e. plants growing both in grasslands and forests (generalists) or mainly in

155 other habitats (e.g. rocks, ruderal habitats). A total of 251 taxa were identified; 139 of them were

156 grassland specialists and 56 were forest specialists (see Online Resource Table S1). 
158 Site variables

159 Habitat availabilities in the historical and current landscapes were obtained as surrogates for habitat

160 connectivity and the abundance of source populations that may contribute to increase species

161 richness for a specific group, rescue remnant populations of grassland specialists and delay

162 extinction (grassland connectivity) (Hanski 1999) or act as propagule sources for colonizing species

163 of forest specialists and accelerate colonization (forest connectivity) (Jacquemyn et al. 2003;

164 Verheyen et al. 2003a). Thus, a specific landscape (500 m radius from site centre) variable for each

165 species group was calculated for both past (1956) and present (2009) combined maps:

166 grassland/forest ratio (for all species), grassland ratio (grassland to non-grassland ratio; habitat

167 availability for grassland specialists) and forest ratio (forest to non-forest ratio; habitat availability

168 for forest specialists). Since sets of proportions can lead to intrinsic correlation of components

169 (Aitchison 1982), they are more properly expressed in terms of log-ratios (Aitchison 1982; Kühn et 170 al. 2006).

172 Plot variables

173 At each plot, soil variables, solar radiation availability and grazing presence-absence were obtained

174 to study the effect of local habitat conditions that might be relevant to species richness of some

175 species groups and might delay or accelerate extinction of grassland specialists or colonization of

176 forest specialists in different situations along the forest encroachment gradient. Soil depth was

177 obtained by the mean of three measures made at each plot, and a single soil sample was taken up to

178 a depth of $10 \mathrm{~cm}$ to analyse soil $\mathrm{pH}$ and texture (clay proportion). Soil depth is related to water

179 availability and $\mathrm{pH}$ may favour grassland specialists (mainly calcicolous), while the high cation

180 exchange capacity of clay enhances soil fertility and water retention and might favour species

181 richness where water is limiting (Cornwell and Grubb 2003). Solar radiation availability, wich is

182 important for the establishment of grassland specialists (Öckinger et al. 2006), was measured using 
183 a ceptometer (AccuPAR LP-80; Decagon Devices, Inc.), and expressed as the ratio of the proportion

184 of Photosynthetic Active Radiation (PAR) reaching understorey plants to the proportion absorbed or 185 reflected by the tree cover. Grazing from livestock and/or roe deer, which might favour grassland 186 species, was assessed at each plot as present or absent. All these drivers of species richness can potentially delay or accelerate extinctions and colonizations of habitat specialists during forest encroachment. In addition, historical and current tree cover proportion was obtained for each plot, in a radius of $10 \mathrm{~m}$, from the combined maps (see Online Resource Table $\mathrm{S} 2$ for descriptive statistics of response variables and predictors). In order to study extinction-colonization dynamics and understand local habitat and landscape effects on species richness at plot scale, the 260 plots were categorised in three situations along the habitat change gradient: persistent grasslands (less than $50 \%$ tree cover in the past and nowadays; 84 plots), wooded grasslands (less than $50 \%$ tree cover in the past and more than $50 \%$ in the present; 156 plots) and persistent forests (more than $50 \%$ tree cover in the past and nowadays; 20 plots). Current tree cover in wooded grassland plots $(0.72 \pm 0.12$; mean \pm SD) did not statistically differ from that in persistent forest plots $(0.75 \pm 0.07$; $P=0.57$; tested using a general linear mixed model relating current tree cover with plot category, site as random factor, and a post-hoc Tukey test). The continuous landscape gradient formed after forest encroachment results in the coexistence of persistent grasslands, wooded grasslands and/or persistent forests within almost all sites (see Fig. 2).

Statistical analyses

203 For the purpose of investigating the plant extinction-colonization balance after the forest encroachment process and testing for the existence of an extinction debt for grassland specialists and a colonization credit for forest specialists, a general linear mixed model (LMM) for each species group (all species, grassland specialists and forest specialists) was conducted, with species richness as the response variable, site as random factor and plot category as the only fixed factor.

208 Then, in order to test for the differences in richness between situations along the habitat change 
gradient and detect extinction debt and colonization credit, a post-hoc Tukey test was performed for

210 each model. Significantly higher richness of grassland specialists at wooded grasslands than at

211 persistent forests would reveal an extinction debt. Similarly, significantly lower richness of forest

212 specialists at wooded grasslands than at persistent forests would indicate a colonization credit.

213 General linear mixed models were conducted using nlme R package (Pinheiro et al. 2014), and the

214 post-hoc Tukey tests were performed using package multcomp in R (Hothorn et al. 2008). A

215 Moran's I test was conducted on the residuals of each model to test for spatial autocorrelation in the

216 residuals. In order to estimate the magnitude of extinction debt and colonization credit, we

217 calculated the difference between mean richness of each specialist group at wooded grasslands and

218 stable forests, for grassland and forest specialists, respectively.

219 Finally, another set of general linear mixed models (LMMs) was constructed for all species (total 220 richness) and for each of the specialist species groups to investigate the local and landscape drivers 221 of species richness and to elucidate the mechanisms of species extinctions and colonizations along

222 the forest encroachment process. Models included the relationship between species richness

223 (response variable), site (random factor), and local and landscape variables in interaction with plot

224 category (fixed effects). Variables expressed as a ratio were log-transformed to improve their

225 normality. A model selection using dredge function in the MuMIn R package (Bartoń 2014) was

226 conducted on each of the previous saturated models, fitted by maximum likelihood (ML), as

227 comparisons between models fitted by restricted maximum likelihood (REML) that vary in their

228 fixed effects are not valid (Weiss 2005). The resulting models were ranked by AICc and the one

229 with all parameters significant at $P=0.05$ and lowest AICc was chosen and fitted by restricted

230 maximum likelihood (REML). When interactions between plot category and a covariable were

231 present, a post-hoc Tukey test was conducted in order to investigate significantly different

232 covariable effects for different plot categories. In addition, spatial autocorrelation in the residuals of

233 the three models was checked using Moran's I tests. 


\section{Results}

238 We found a significant decrease of $32 \%$ (9.8 species on average) in total plant richness from

239 persistent grassland to persistent forest plots (see Fig. 3), but no richness differences between

240 wooded grasslands and any persistent habitat, tested using a general linear mixed model with site as

241 random factor, and a post-hoc Tukey test (Table 1; Online Resource Fig. S1).

242 As expected, the highest species richness of grassland specialists was found in persistent

243 grassland plots (26.6 species), it was intermediate in wooded grasslands (17.3 species), and lowest

244 in persistent forests (7.9 species; see Fig. 3). Using persistent forest plots as a reference, the

245 extinction debt for grassland specialists in wooded grassland plots was 54.6\% (9.4 species on

246 average per plot).

247 Forest specialists showed almost the inverse pattern, having the lowest observed richness in

248 persistent grasslands (2.3 species on average per plot). However, richness of forest specialists did

249 not statistically differ between wooded grasslands (7.0 species) and persistent forests (10.2 species)

250 according to the general linear mixed model (Table 1), even though there is a tendency to richness

251 increase along the forest encroachment process (Online Resource Fig. S1). Although no significant

252 colonization credit for forest specialists was found, the tendency to richness increase from wooded

253 grasslands to persistent forests (3.2 species on average per plot) was supported by a relatively low

$254 P$-value $(P=0.13)$, and the average species richness increase represented $45.7 \%$ of the forest

255 specialist species currently present in wooded grasslands. Predicted values for each plot category

256 are shown in Online Resource Table S3.

257 Additional linear mixed models were performed to identify the local and landscape variables that

258 affect the species richness of all species, grassland specialists and forest specialists and that may

259 delay or accelerate extinctions of grassland specialists and colonizations of forest specialists.

260 According to the best model, total richness was determined by soil $\mathrm{pH}$, solar radiation availability 
261 (both positively correlated), and interaction between plot category and current landscape (ratio of

262 grassland/forest) and local predictors (soil clay proportion and soil depth) (see also Online Resource

263 Table S4, Fig. S2 for results and effect plots). The model accounted for $52 \%$ of variation in total

264 richness, according to the likelihood-ratio based pseudo- $\mathrm{R}^{2}$ (Magee 1990). Post-hoc Tukey tests

265 revealed that grassland/forest ratio in the current landscape decreased total richness in persistent

266 grasslands significantly more than in wooded grasslands (for the latter, the relationship was slightly

267 positive). Clay proportion had a higher positive effect in persistent grasslands than in wooded

268 grasslands, and the negative effect of soil depth on total species richness was significantly higher in

269 persistent grasslands than in wooded grasslands, although no much difference can be observed.

270 The best model for grassland specialist richness had a high pseudo- $\mathrm{R}^{2}$ of $(0.71)$ and comprised

271 solar radiation availability, soil $\mathrm{pH}$, grassland availability in the current landscape (all three having

272 positive effects), soil depth (negatively correlated), and the factor plot category (Table 2). No

273 interaction between plot category and any of the variables was included in the model, indicating that

274 the drivers of the richness of grassland specialists are held constant along the forest encroachment

275 process.

276 For forest specialists, the selected model on species richness had a very similar pseudo- $\mathrm{R}^{2}$ to the

277 model for grassland specialists. It included solar radiation availability (negatively correlated), and

278 the interaction between plot category and historical landscape forest availability and clay

279 proportion. Historical forest connectivity had a positive effect on richness in persistent grasslands

280 and wooded grasslands, while it was slightly negative in persistent forests. Clay proportion had a

281 slightly positive effect on richness of forest specialists in persistent grasslands and a slightly

282 negative effect in wooded grasslands, although the differences are barely noticeable (Online

283 Resource Fig. S2). No significant spatial autocorrelation was found for any of the models. 
288 In this work we focus on the simultaneous extinction-colonization dynamics of two specialist

289 species groups in a successional habitat transition. Our landscape sampling approach, based on

290 regularly distributed plots within selected sites across the landscape, has proven able to identify

291 time lags and their drivers in a variegated landscape with fine-scale habitat transitions resulting

292 from the forest encroachment process. Thus, our study detects extinction debt but not significant

293 colonization credit for grassland and forest specialists, respectively, at plot scale $\left(7 \mathrm{~m}^{2}\right)$ after several

294 decades of forest encroachment into semi-natural Mediterranean grasslands. The study also finds a

295 significant decline of $32 \%$ in total species richness as the outcome of this habitat change. Still, the

296 study shows that species richness of all groups is influenced by both landscape and local habitat

297 characteristics, but the effect of these characteristics differs between species groups.

299 Patterns of richness change

300 As expected, species richness of grassland specialists is higher in persistent grasslands than in the 301 other two studied habitats along the habitat change gradient. Beyond this trivial result, however, 302 species richness of this group is significantly higher in wooded grasslands than in persistent forests, 303 despite no significant differences were found in tree cover between these habitats. Moreover, 55\%

304 of grassland specialist species in wooded grasslands are expected to become extinct in the future,

305 indicating the existence of a large extinction debt after forest encroachment, even though the 306 process started more than 50 years ago. Extinction debt of grassland specialists has also been 307 observed in grassland patches in the same region (Guardiola et al. 2013) and in other calcareous 308 grasslands (e.g. Helm et al. 2006; Krauss et al. 2010; Cousins and Vanhoenacker 2011; but see 309 Adriaens et al. 2006). Vellend et al. (2006) and Cousins and Vanhoenacker (2011) found that 310 extinction debt in plants might persist for more than a century following habitat fragmentation.

311 Many grassland plants exhibit perennial life-cycles with long life-spans (Krauss et al. 2010) and, 312 consequently, long relaxation times after habitat change are expected (Kuussaari et al. 2009), 
313 though other factors like rescue effect cannot be discarded. What is new in our study is the evidence

314 that this extinction debt might persist for decades in the new wooded habitats resulting from

315 grassland substitution.

316 Highest species richness of forest specialists is found, also as expected, in persistent forest plots,

317 although it is not significantly different from that in wooded grasslands. High variability in forest

318 species' richness, the low number of persistent forest plots and the fact that many of these plots

319 belong to one site might explain the non-significance of this trend. Thus, we do not find evidence of

320 a significant colonization credit coexisting with the extinction debt of grassland specialists.

321 Colonization credits have not yet been widely studied, but they have been already identified in

322 different habitats and for several taxonomic groups, such as plants (Pierik et al. 2010; Piqueray et

323 al. 2011; Başnou et al. 2015), mosses (Hylander and Weibull 2012), and birds and small mammals

324 (Lira et al. 2012). However, they have not been detected in some newly restored habitats like

325 heathlands (Cristofoli et al. 2010). Only few of these studies also investigated the coexistence of

326 extinction debts and colonization credits following habitat change, but they put the focus on a given

327 habitat type instead of on the complete habitat series (Piqueray et al. 2011; Lira et al. 2012), or on

328 the complete community instead of the specialist species groups (Hylander and Weibull 2012). Our

329 study extend these previous works through dealing with the whole habitat sequence along the

330 successional transition from grasslands to forests, and doing so separately for the specialist species

331 of each habitat.

332 Jackson and Sax (2010) indicated the importance of the magnitude and chronology of extinction

333 debt and colonization credit on the community biodiversity balance over time. Although our study

334 finds a significant decrease in total species richness as the outcome of the process, it also suggests

335 that extinctions and colonizations of plant specialists might have occurred simultaneously following

336 forest encroachment, as no richness surplus or deficit was observed in total species across the

337 encroachment process (plant richness in wooded grasslands does not statistically differ from any of

338 the stable habitats), although at not identical rate. Our results suggest that colonization credit of 
339 forest specialists is being paid faster than extinction debt of grassland specialists (actually, forest

340 specialists' richness does not statistically differ between wooded grasslands and persistent forests,

341 while that of grassland specialists does), probably due to its smaller magnitude. Helm et al. (2015)

342 showed that with decreasing grassland size, total number of species on sites can even increase due

343 to influx of generalist species and species not characteristic to a given habitat, while the number of

344 characteristic species remains the same due to extinction debt. This indicates that expected

345 colonizations can occur (at least partly) faster than extinctions, resulting in temporal enrichment of

346 flora due to simultaneous coexistence of different species pools. It should be noted that the

347 persistent forest plots used in our study as a reference to calculate extinction debts and colonization

348 credits are not old-growth forests, and the fact that they were managed and cleared in the past may

349 explain why a nonnegligible number of grassland specialist plant species are still present. Also, an

350 unknown number of forest specialists might be absent from these historically managed forests

351 (Grove and Rackham 2001; Başnou et al. 2015), thus limiting forest species richness in persistent

352 forests and colonization credit in wooded grasslands. If we considered that all grassland specialist

353 species will ultimately go extinct and more forest specialists will still colonize persistent forests, the

354 magnitude of both extinction debt and colonization credit would be even greater. However, a

355 thorough study would be needed to predict the species richness of old-growth forests in the area that

356 would allow the accurate calculation of extinction debt and colonization credit, because species

357 richness can be influenced by very long-term historical effects (e.g. Dambrine et al. 2007). The

358 study of extinction debt and colonization credit dynamics following a land-use change event is

359 needed to understand how community change occurs over time (Jackson and Sax 2010). A good

360 knowledge of initial and final habitat situations is also crucial to assess the magnitude of both debts

361 and credits and to identify potential transient situations of richness surplus or deficit that would

362 allow further understanding on the interaction of both processes.

364 Local and landscape drivers of richness change 
365 Evaluating the separate response of each species group to the studied local habitat conditions and

366 landscape factors can elucidate some of the richness patterns detailed above and the mechanisms

367 involved in delayed extinctions and colonizations following forest encroachment.

368 For grassland specialists, high connectivity for the focal habitat in the landscape exerts a positive

369 effect on species richness for this group in all situations along the habitat encroachment gradient.

370 Thus, grassland connectivity might enhance persistence of grassland specialist species both in

371 optimal and degraded habitats. In previous works, a rescue effect from nearby populations was

372 suggested as a mechanism for delayed extinctions (Kuussaari et al. 2009; Krauss et al. 2010), but

373 we did not find a specific effect on transient habitats that might point to that mechanism. Solar

374 radiation and soil $\mathrm{pH}$ enhance species richness for this group; the former is known to promote the

375 establishment of grassland specialists, while the positive association of $\mathrm{pH}$ with grassland species

376 richness might be due to the fact that open habitats exhibit mildly alkaline soils in the study area,

377 probably because of the negative association between $\mathrm{pH}$ and soil organic matter $(r=-0.55)$, which

378 mostly accumulates under tree canopies. In addition, soil depth shows a negative effect on the

379 richness of grassland specialists, probably due to the already known competition effects of high

380 resource availability (Grime 2001).

381 For forest specialists, higher historical forest availability in the landscape enhances plant richness

382 in wooded and persistent grasslands, while it has no effect in persistent forests. It suggests that

383 colonization is enhanced by connectivity where there is still a lack of forest species, reinforcing the

384 idea that a colonization credit might exist despite richness of forest specialists was not significantly

385 lower in wooded grasslands than in persistent forests. The positive relationship with historical but

386 not with current forest connectivity suggests that the potential colonization credit depends on the

387 historical forest extent and it can persist for a long time (Jacquemyn et al. 2003; Vellend 2003).

388 Moreover, recently forested areas are likely to be less rich in forest specialist plants than historical

389 forests and, consequently, they might act as poorer seed sources, delaying the colonization process.

390 Clay proportion has a slightly negative effect on forest species richness in wooded grasslands 
compared to persistent grasslands. Despite these differences are very small, it might indicate that

392 increased soil fertility and water retention due to clay could improve habitat quality for forest

393 species in persistent grasslands, where water is limiting. Finally, as expected, low solar radiation

394 availability favours richness of forest specialists, as these plants thrive under tree canopies, and this

395 effect is independent of the habitat gradient situation.

396 Habitat condition and landscape factors have contrasting effects on total species richness, which

397 depend on habitat type and are partially attributable to the effects on plant specialist groups reported

398 above (see Online Resource Table S4, Fig. S2).

400 Implications for management

401 Both extinction debts and colonization credits constitute a great challenge for the conservation of

402 biodiversity, but their integration has been rarely addressed, despite considerable literature on

403 delayed extinctions and an increasing interest on delayed colonizations after the Jackson and Sax

404 (2010) review. The simultaneous detection of these processes and the investigation of their potential

405 correlates are needed to understand, assess, and mitigate biodiversity changes that might take place

406 in the future and their effects. We have proven that both local and landscape drivers contribute to set

407 species richness of the biodiversity groups involved in habitat change. Moreover, these drivers may

408 strongly vary along the habitat change gradient, affecting to a different extent species persistence

409 and, likely, dispersal at different stages of the process, and for different specialist species groups.

410 Hence, considering variation in the drivers along habitat change gradients and across species groups

411 is crucial to understand the overall process of extinction-colonization following a forcing event.

412 Although an important habitat change might have occurred, as long as the species predicted to

413 become extinct still persist and those predicted to colonize have not arrived yet, there is time for

414 conservation measures such as habitat restoration and landscape management. However, in order to

415 conduct an effective restoration it is crucial to rely on information about the relation of extinction

416 debt to habitat quality deterioration, connectivity loss, and small populations' susceptibility to 
genetic deterioration or environmental and demographic stochasticity (Hylander and Ehrlén 2013).

418 This is especially important in habitats of high conservation value such as European semi-natural

419 grasslands.

420 As the loss of semi-natural grasslands in favour of arable fields or forests has been a general

421 trend during the last century in Europe (Eriksson et al. 2002; Adriaens et al. 2006), we still expect a

422 general decline in grassland specialists' populations if no conservation measures are taken.

423 Moreover, an increase in forest specialists might be also expected in the following years or decades

424 due to generalised forest encroachment (Debussche et al. 1999). Therefore, extinctions and

425 probably colonizations will continue to occur even if no more habitat loss takes place, causing a

426 slow but steady biodiversity decline over several decades in these previously widespread semi-

427 natural grasslands, while forest species become more common as extinction debt and colonization

428 credit are paid. However, since extinction debt exceeds colonization credit in these habitats, the

429 community is expected to undergo net species loss after all extinctions and colonizations occur, as

430 pointed out by the strong total richness decline from persistent grasslands to persistent forests.

433 Acknowledgements We thank M. Guardiola for fieldwork and plant identification support, L. Sáez

434 for aid in plant identification, G. Esparza for fieldwork assistance, J.M. Ninot for advice on plant

435 specialists lists, P. Vicente for digitising the orthophotomap of 1956 and performing the training

436 points for orthophotomaps' reclassification, M. Pärtel for advice in conducting the analyses, and

437 him and two anonymous referees for valuable comments on the manuscript. This study was funded

438 by MICINN (Spain) in the project LANDPOLNET (CGL2009-12646) and by the Spanish

439 Consolider-Ingenio 2010 programme in the project MONTES (CSD2008-00040). G. Bagaria was

440 supported by a Pre-doctoral FPU fellowship (AP2009-4599) from the Ministerio de Educación y

441 Ciencia (Spain). A. Helm was supported by Estonian Research Council (grant no 9223) and by the

442 EU through the European Regional Development Fund (Centre of Excellence FIBIR). The 
443 experiments comply with the current laws of the country (Spain) in which the experiments were

444 performed.

445

446 Conflict of Interest The authors declare that they have no conflict of interest.

449 References

450

451 Adriaens D, Honnay O, Hermy M (2006) No evidence of a plant extinction debt in highly

452 fragmented calcareous grasslands in Belgium. Biol Conserv 133:212-224. doi:

$453 \quad 10.1016 /$ j.biocon.2006.06.006

454 Aitchison J (1982) The statistical analysis of compositional data. J R Stat Soc Ser B 44:139-177.

$455 \quad$ doi: $10.2307 / 2345821$

456 Baan L, Alkemade R, Koellner T (2012) Land use impacts on biodiversity in LCA: a global approach. Int J Life Cycle Assess 18:1216-1230. doi: 10.1007/s11367-012-0412-0

Bagaria G, Pino J, Rodà F, Guardiola M (2012) Species traits weakly involved in plant responses to landscape properties in Mediterranean grasslands. J Veg Sci 23:432-442. doi: 10.1111/j.1654-

Bartoń K (2014) MuMIn: Multi-model inference. R package version 1.10.0. http://cran.rproject.org/package $=$ MuMIn

Başnou C, Vicente P, Espelta JM, Pino J (2015) Of niche differentiation, dispersal ability and historical legacies: what drives woody community assembly in recent Mediterranean forests? Oikos. doi: 10.1111/oik.02534

Bolòs O, Vigo J, Masalles RM, Ninot JM (2005) Flora manual dels Països Catalans. Pòrtic, 
468 Cornwell WK, Grubb PJ (2003) Regional and local patterns in plant species richness with respect to 469 resource availability. Oikos 100:417-428. doi: 10.1034/j.1600-0706.2003.11697.x

470 Cousins SAO, Vanhoenacker D (2011) Detection of extinction debt depends on scale and $471 \quad$ specialisation. Biol Conserv 144:782-787. doi: 10.1016/j.biocon.2010.11.009

472 Cristofoli S, Piqueray J, Dufrene M, Bizoux J, Mahy G (2010) Colonization credit in restored wet 473 heathlands. Restor Ecol 18:645-655. doi: 10.1111/j.1526-100X.2008.00495.x

474 Dambrine E, Dupouey J-L, Laüt L, Humbert L, Thinon M, Beaufils T, Richard H (2007) Present 475 forest biodiversity patterns in France related to former Roman agriculture. Ecology 88:1430476 1439. doi: 10.1890/05-1314

Debussche M, Lepart J, Dervieux A (1999) Mediterranean landscape changes: evidence from old postcards. Glob Ecol Biogeogr 8:3-15.

Díaz-Villa MD, Marañón T, Arroyo J, Garrido B (2003) Soil seed bank and floristic diversity in a forest-grassland mosaic in southern Spain. J Veg Sci 14:701-709. doi: 10.1111/j.1654-

Eriksson O (1996) Regional dynamics of plants: A review of evidence for remnant, source-sink and 483 metapopulations. Oikos 77:248-258. doi: 10.2307/3546063

Eriksson O, Cousins SAO, Bruun HH (2002) Land-use history and fragmentation of traditionally managed grasslands in Scandinavia. J Veg Sci 13:743-748. doi: 10.1111/j.16541103.2002.tb02102.x

Fahrig L (2003) Effects of habitat fragmentation on biodiversity. Annu Rev Ecol Evol Syst 34:487515. doi: 10.1146/annurev.ecolsys.34.011802.132419

489 Grime JP (2001) Plant strategies, vegetation processes, and ecosystem properties. John Wiley and $490 \quad$ Sons, Chichester

491 Grove AT, Rackham O (2001) The nature of Mediterranean Europe: An ecological history. Yale 
493 Guardiola M, Pino J, Rodà F (2013) Patch history and spatial scale modulate local plant extinction 494 and extinction debt in habitat patches. Divers Distrib 19:825-833. doi: 10.1111/ddi.12045

495 Hanski I (2000) Extinction debt and species credit in boreal forests: modelling the consequences of 496 different approaches to biodiversity conservation. Ann Zool Fennici 37:271-280

497 Hanski I (1999) Metapopulation ecology. Oxford University Press, Oxford

498 Helm A, Hanski I, Pärtel M (2006) Slow response of plant species richness to habitat loss and 499 fragmentation. Ecol Lett 9:72-77. doi: 10.1111/j.1461-0248.2005.00841.x

500 Helm A, Zobel M, Moles AT, Szava-Kovats R, Pärtel M (2015) Characteristic and derived diversity: 501 implementing the species pool concept to quantify conservation condition of habitats. Divers Distrib 21:711-721. doi: 10.1111/ddi.12285

503 Hothorn T, Bretz F, Westfall P (2008) Simultaneous inference in general parametric models.

Hylander K, Ehrlén J (2013) The mechanisms causing extinction debts. Trends Ecol Evol 28:341Biometrical J 50:346-363. doi: 10.1002/bimj.200810425

Hylander K, Weibull H (2012) Do time-lagged extinctions and colonizations change the 346. doi: 10.1016/j.tree.2013.01.010 interpretation of buffer strip effectiveness? - a study of riparian bryophytes in the first decade after logging. J Appl Ecol 49:1316-1324. doi: 10.1111/j.1365-2664.2012.02218.x

Jackson ST, Sax DF (2010) Balancing biodiversity in a changing environment: extinction debt,

513 Jacquemyn H, Butaye J, Hermy M (2003) Influence of environmental and spatial variables on 514 regional distribution of forest plant species in a fragmented and changing landscape.

515 Ecography 26:768-776. doi: 10.1111/j.0906-7590.2003.03620.x 
516 Krauss J, Bommarco R, Guardiola M, Heikkinen RK, Helm A, Kuussaari M, Lindborg R, Öckinger

517 E, Pärtel M, Pino J, Pöyry J, Raatikainen KM, Sang A, Stefanescu C, Teder T, Zobel M,

518 Steffan-Dewenter I (2010) Habitat fragmentation causes immediate and time-delayed

519 biodiversity loss at different trophic levels. Ecol Lett 13:597-605. doi: 10.1111/j.1461-

$520 \quad$ 0248.2010.01457.x

521 Kühn I, Bierman SM, Durka W, Klotz S (2006) Relating geographical variation in pollination types 522 to environmental and spatial factors using novel statistical methods. New Phytol 172:127-139. 523 doi: $10.1111 / \mathrm{j} .1469-8137.2006 .01811 . x$

524 Kuussaari M, Bommarco R, Heikkinen RK, Helm A, Krauss J, Lindborg R, Öckinger E, Pärtel M, 525 Pino J, Rodà F, Stefanescu C, Teder T, Zobel M, Steffan-Dewenter I (2009) Extinction debt: a 526 challenge for biodiversity conservation. Trends Ecol Evol 24:564-571. doi:10.1016/j.tree.2009.04.011

Lindborg R, Helm A, Bommarco R, Heikkinen RK, Kühn I, Pykälä J, Pärtel M (2012) Effect of habitat area and isolation on plant trait distribution in European forests and grasslands.

531 Lira PK, Ewers RM, Banks-Leite C, Pardini R, Metzger JP (2012) Evaluating the legacy of landscape history: extinction debt and species credit in bird and small mammal assemblages in

Magee L (1990) $R^{2}$ measures based on Wald and likelihood ratio joint significance tests. Am Stat 44:250-253. doi: $10.2307 / 2685352$

McIntyre S, Barrett GW (1992) Habitat variegation, an alternative to fragmentation. Conserv Biol 6:146-147. doi: 10.1046/j.1523-1739.1992.610146.x

539 Öckinger E, Eriksson AK, Smith HG (2006) Effects of grassland abandonment, restoration and management on butterflies and vascular plants. Biol Conserv 133:291-300. doi: 
542 Pierik M, van Ruijven J, Bezemer T, Berendse F (2010) Travelling to a former sea floor:

543 colonization of forests by understorey plant species on land recently reclaimed from the sea. $\mathrm{J}$

$544 \quad$ Veg Sci 21:167-176. doi: 10.1111/j.1654-1103.2009.01134.x

545 Pinheiro J, Bates D, DebRoy S, Sarkar D, R Core Team (2014) nlme: Linear and nonlinear mixed 546 effects models. R package version 3.1-117. http://cran.r-project.org/package=nlme

547 Piqueray J, Cristofoli S, Palm R, Bisteau E, Mahy G (2011) Testing coexistence of extinction debt 548 and colonization credit in fragmented calcareous grasslands with complex historical dynamics.

$549 \quad$ Landsc Ecol 26:823-836. doi: 10.1007/s10980-011-9611-5

550 Piqueray J, Saad L, Bizoux J-P, Mahy G (2013) Why some species cannot colonise restored 551 habitats? The effects of seed and microsite availability. J Nat Conserv 21:189-197. doi: 10.1016/j.jnc.2012.12.005

R Development Core Team (2014) R: A language and environment for statistical computing. R package version 3.1.0. http://www.r-project.org

Rivas-Martínez S, Fernández-González F, Loidi J, Lousa M, Penas A (2001) Syntaxonomical checklist of vascular plant communities of Spain and Portugal to association level. Itinera Geobot 14:5-341

Sax DF, Brown JH (2000) The paradox of invasion. Glob Ecol Biogeogr 9:363-371. doi: $10.1007 / \mathrm{s} 00442-011-2203-\mathrm{x}$

Therneau T, Atkinson B, Ripley B (2013) rpart: Recursive Partitioning. R package version 4.1-1. http://cran.r-project.org/package=rpart

562 Tilman D, May R, Lehman CL, Nowak MA (1994) Habitat destruction and the extinction debt. Nature 371:65-66. doi: 10.1038/371065a0

564 Vellend M (2005) Land-use history and plant performance in populations of Trillium grandiflorum. 
566 Vellend M (2003) Habitat loss inhibits recovery of plant diversity as forests regrow. Ecology

567 84:1158-1164. doi: 10.1890/0012-9658(2003)084[1158:HLIROP]2.0.CO;2

568 Vellend M, Verheyen K, Jacquemyn H, Kolb A, Van Calster H, Peterken G, Hermy M (2006)

569 Extinction debt of forest plants persists for more than a century following habitat

$570 \quad$ fragmentation. Ecology 87:542-548. doi: 10.1890/05-1182

571 Verheyen K, Guntenspergen GR, Biesbrouck B, Hermy M (2003a) An integrated analysis of the

572 effects of past land use on forest herb colonization at the landscape scale. J Ecol 91:731-742.

573 doi: 10.1046/j.1365-2745.2003.00807.x

574 Verheyen K, Honnay O, Motzkin G, Hermy M, Foster DR (2003b) Response of forest plant species 575 to land-use change: a life-history trait-based approach. J Ecol 91:563-577. doi:

$576 \quad 10.1046 / \mathrm{j} .1365-2745.2003 .00789 . x$

577 Weiss RE (2005) Modeling longitudinal data. Springer, New York. doi:

$578 \quad 10.3109 / 02813439309045499$

579 Zulka KP, Abensperg-Traun M, Milasowszky N, Bieringer G, Gereben-Krenn B-A, Holzinger W,

580 Hölzler G, Rabitsch W, Reischütz A, Querner P, Sauberer N, Schmitzberger I, Willner W,

$581 \quad$ Wrbka T, Zechmeister H (2014) Species richness in dry grassland patches of eastern Austria: A

582 multi-taxon study on the role of local, landscape and habitat quality variables. Agric Ecosyst

583 Environ 182:25-36. doi:10.1016/j.agee.2013.11.016 
585 Table 1. Results of post-hoc Tukey tests on the general linear mixed models (LMMs) comparing

586 species richness between plot categories (PG, persistent grasslands; WG, wooded grasslands, and

$587 \mathrm{PF}$, persistent forests) for each species group. Estimates, standard errors (SE) and $P$-values are given

588 for comparisons between all pairs of plot categories (columns). Each row corresponds to a model

589 for a species group (all species, grassland specialists and forest specialists). Significantly different

590 comparisons are marked in bold, and likelihood-ratio based pseudo- $\mathrm{R}^{2}$ for each model is given

591

\begin{tabular}{|c|c|c|c|c|c|c|c|}
\hline & \multicolumn{2}{|c|}{ Plot category (WG - PG) } & \multicolumn{2}{|c|}{ Plot category (PF - PG) } & \multicolumn{2}{|c|}{ Plot category (PF - WG) } & \multirow{2}{*}{$\mathrm{R}^{2}$} \\
\hline & Estimate $\pm \mathrm{SE}$ & $P$-value & Estimate $\pm \mathrm{SE}$ & $P$-value & Estimate $\pm \mathrm{SE}$ & $P$-value & \\
\hline All species & $-1.24 \pm 1.20$ & 0.540 & $-6.43 \pm 2.66$ & $\mathbf{0 . 0 3 8}$ & $-5.18 \pm 2.59$ & 0.103 & 0.31 \\
\hline Grassland specialists & $-4.05 \pm 1.14$ & 0.001 & $-10.64 \pm 2.60$ & $<0.001$ & $-6.59 \pm 1.66$ & 0.022 & 0.57 \\
\hline Forest specialists & $1.99 \pm 0.38$ & $<0.001$ & $3.60 \pm 0.88$ & $<0.001$ & $1.61 \pm 0.86$ & 0.134 & 0.66 \\
\hline
\end{tabular}


594 Table 2. Results of selected models for determinants of species richness for grassland specialists and forest

595 specialists. The model with all parameters significant and lowest AICc was selected and fitted by restricted

596 maximum likelihood (REML). Significant predictors and interactions at $P<0.05$ are marked in bold, those

597 that are significant only in an interaction term are included as main effects, and those not selected are not

598 included. Estimates and $P$-values for all pair-wise comparisons between factor levels (for the factor plot

599 category and interactions between it and a covariable) were obtained using post-hoc Tukey tests. PG,

600 persistent grasslands; WG, wooded grasslands, and PF, persistent forests

Grassland specialists

Forest specialists

Predictor

Estimate \pm SE

Estimate \pm SE

(Intercept)

$5.62 \pm 4.86$

$8.01 \pm 1.67$

Plot category (WG - PG)

$-1.56 \pm 0.99$

$2.62 \pm 1.28$

Plot category (PF - PG)

$-6.87 \pm 2.20$

$-3.84 \pm 3.28$

Plot category (PF - WG)

$-5.32 \pm 2.10$

$-6.47 \pm 3.07$

Historical landscape ${ }^{\mathrm{a}}$

$3.04 \pm 0.98$

Current landscape ${ }^{\mathrm{b}}$

7.20 \pm 3.29

Solar radiation availability log-ratio

$1.71 \pm 0.22$

$-0.22 \pm 0.09$

Clay proportion

$3.46 \pm 2.50$

Soil pH

$3.08 \pm 0.58$

Soil depth

$-0.10 \pm 0.04$ 
Historical landscape ${ }^{1} *$ Plot category (WG - PG)

Historical landscape ${ }^{1} *$ Plot category (PF - PG)

Historical landscape ${ }^{1} *$ Plot category $(\mathrm{PF}-\mathrm{WG})$

Clay proportion*Plot category (WG - PG)

Clay proportion*Plot category (PF - PG)

Clay proportion*Plot category (PF - WG)

Likelihood-ratio based pseudo- $\mathrm{R}^{2}$
$-4.64 \pm 1.60$

$-4.19 \pm 1.51$

$-7.49 \pm 3.19$

$5.30 \pm 6.82$

$12.79 \pm 6.61$

601

$602{ }^{a}$ For grassland specialists model: grassland/all other habitats log-ratio i.e. grassland availability in

603 historical landscape; for forest specialists model: forest/all other habitats log-ratio i.e. forest

604 availability in historical landscape.

$605{ }^{\mathrm{b}}$ For grassland specialists model: grassland/all other habitats log-ratio i.e. grassland availability in

606 current landscape; for forest specialists model: forest/all other habitats log-ratio i.e. forest

607 availability in current landscape.

608 


\section{FIGURE LEGENDS}

Fig. 1 Maps showing a) location of the study area in the Iberian Peninsula and b) distribution of the study sites in the Prades Mountains (800 m contour line) over the land-cover map of 2009. Specific site locations showing c) the spatial scale of study sites and d) the distribution of sampling plots within a site

Fig. 2 a) Historical and b) current orthophotomaps from a study site showing how plot tree cover was calculated to determine plots with few changes from previous grasslands (persistent grasslands), woody encroachment into previous grasslands (wooded grasslands), and few changes from previously wooded plots (persistent forests)

Fig. 3 Observed richness per sampling plot of different plant species groups along the woody encroachment gradient. Bars are means $\pm 1 S E$ for each species group 


\section{FIGURES}

Fig. 1

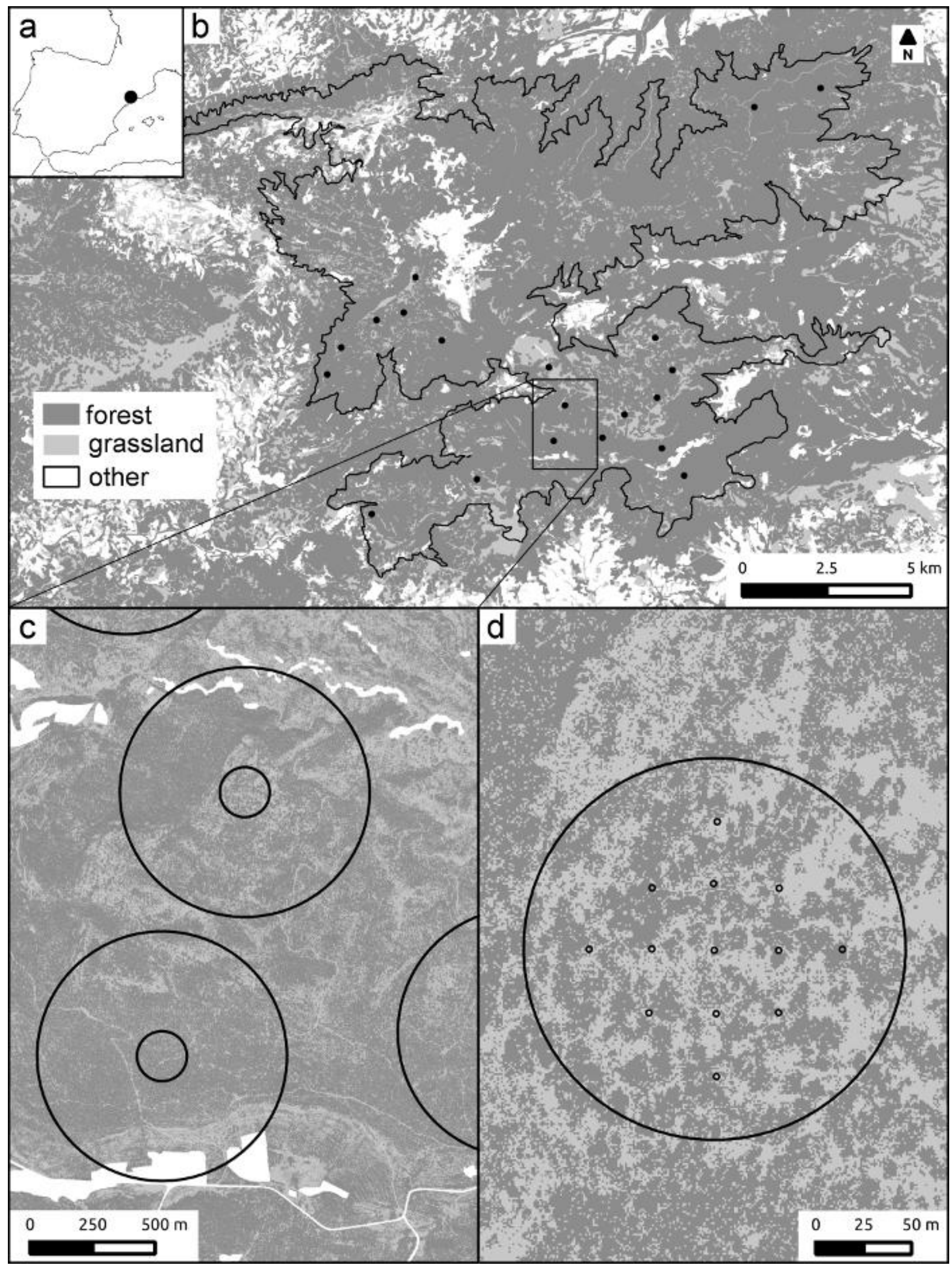


Fig. 2

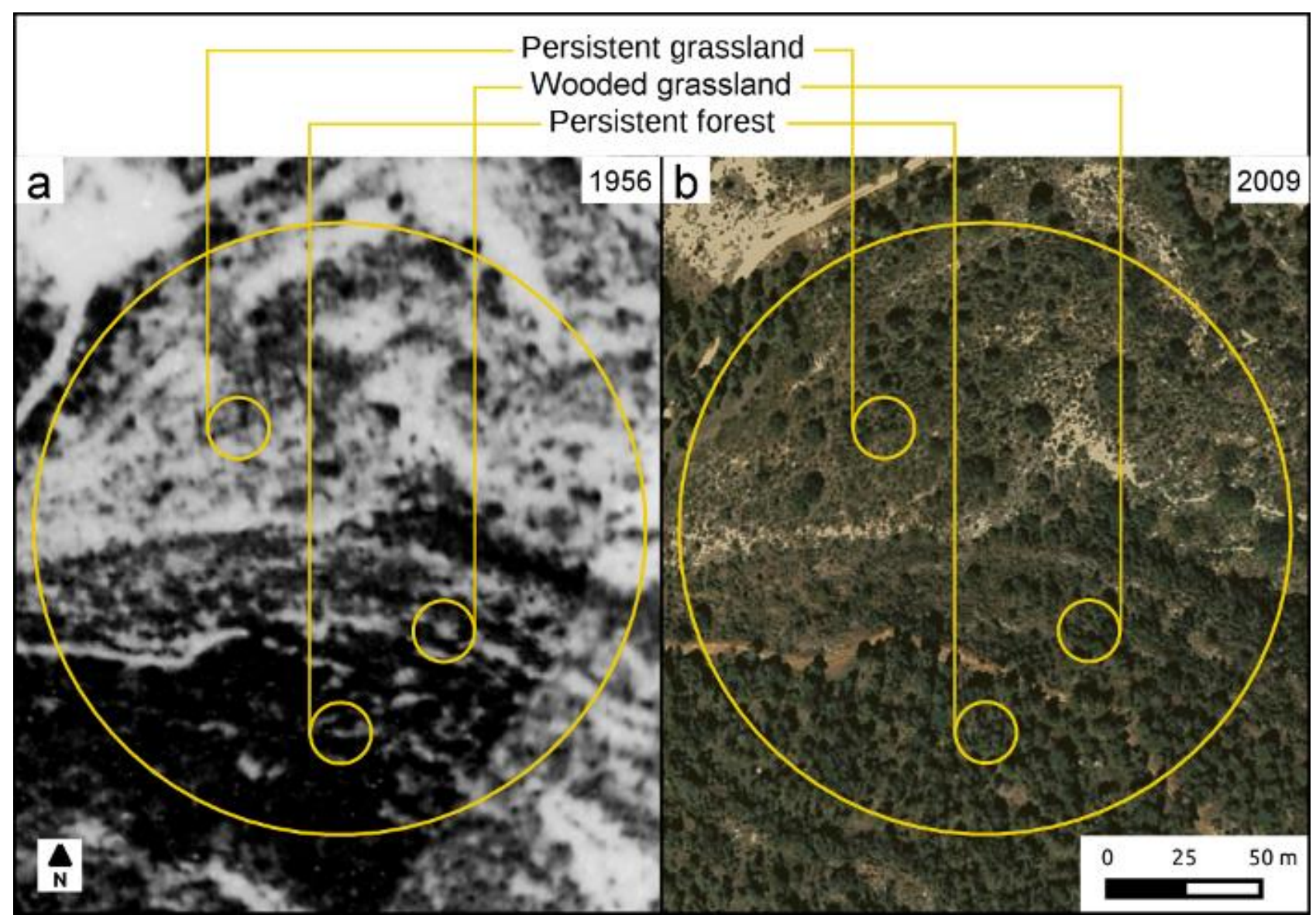


Fig. 3

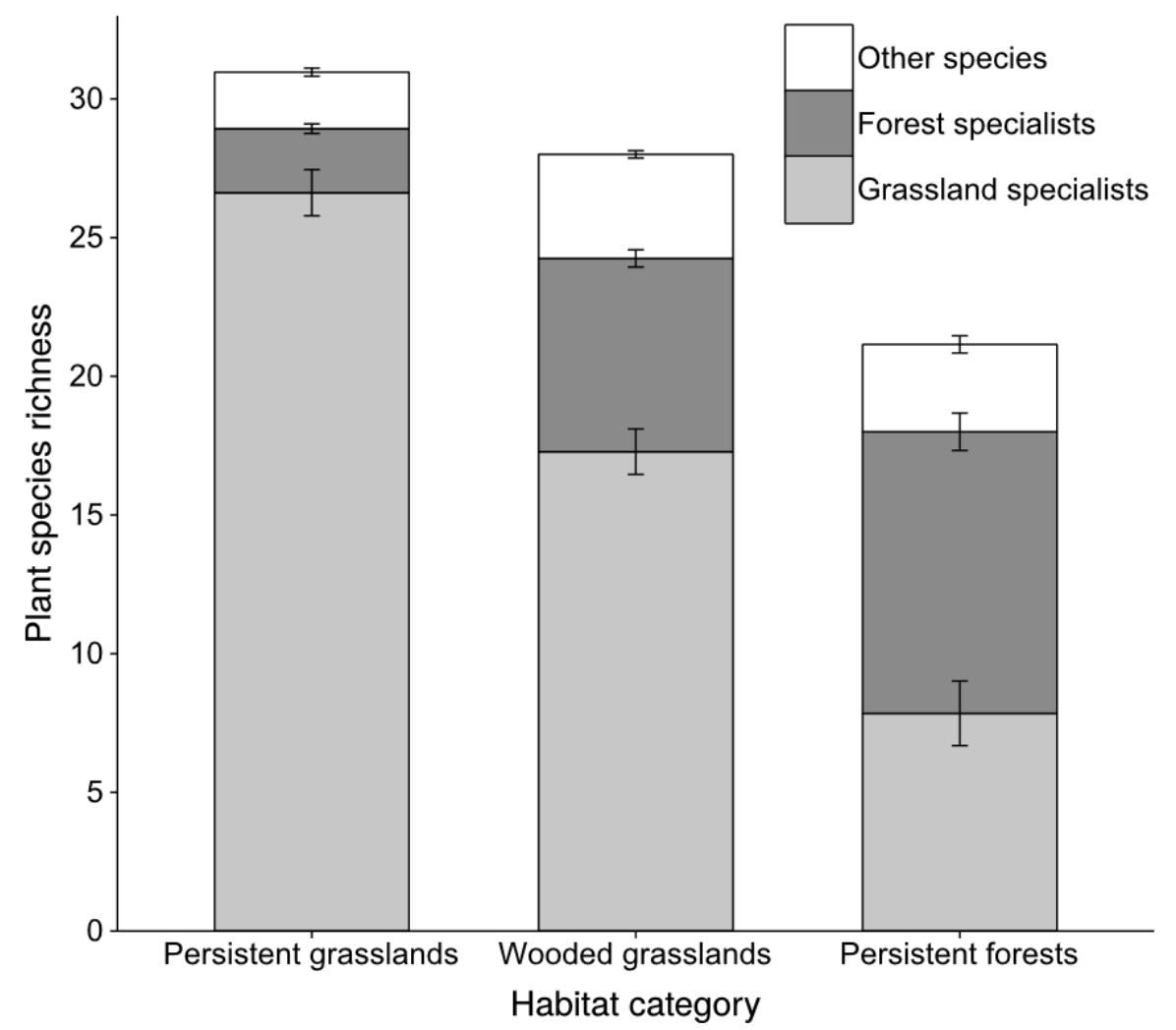

